Accepted for publication in International Journal of Lifelong Education, 25, 1

\title{
The in-between: exposing everyday learning at work
}

Nicky Solomon, David Boud and Donna Rooney

University of Technology, Sydney

\begin{abstract}
Much has been written about how space and time are integral to understanding social relations, in particular about associations between space and understanding learning in workplaces. Drawing from a research study exploring everyday learning at work, this paper looks beyond what is generally understood as work situations by turning to those spaces and times where 'social' and 'work' overlap, such as breaks in tearooms. These spaces are not so work orientated that they can be described as 'workspaces', nor they are entirely social. The nexus between work and the social, of being a worker and a social being, of engaging in legitimate work and socialising are put forward as rich expanses for everyday learning.
\end{abstract}

The paper draws on interviews and observational data from four work sites within one organization. It undertakes an exploration of the intersection of space, time and informal learning with regard to the social/work spaces located at work. It argues that a key location for everyday learning at work is at the points of intersection between work and social spaces and that it is necessary to abandon simplistic dichotomies between work, social and learning space.

The social and physical environment of the workplace has a profound influence on work itself, the relationships between workers and their work and the personal lives of workers. How we learn to do our job and how we deal with the challenges we face in doing so are framed within this context. Part of this context is the social and physical spaces we occupy, the times we spend in them and the ways in which they shape our experience. This paper is concerned with the ways in which ideas of space are helpful in thinking about workplace learning. Indeed the term workplace learning itself draws our attention to its place or space. In other words workplace learning has particular kinds of meanings and practices because of its location and because that location is not an 
educational institution. Similarly, understandings of on-the-job learning are connected to the place of that kind of learning and, in particular that this place is not off the job.

Our interest reflects the significance of 'space' in contemporary social and cultural theory as well as the increasing use of space metaphors in understanding the changing place of education, knowledge and learning in the contemporary moment. Unlike formal training or professional development, there is relatively little research on everyday learning and the ways in which the informal world of the workplace might be mobilized by workers, or enhanced by employers. Similarly, while learning and space have intimate associations (Jamieson et al, 2000), it is formal learning environments that attract most attention (Edwards and Clarke, 2002). Much has been written about how space and time are integral to understanding social relations (Nespor, 1994) and in turn understanding learning in workplaces (Clarke et al, 2002; Edwards \& Clarke, 2002; O'Toole, 2001). Furthermore, there are studies that draw parallels between space and identity (Groat, 1995), and those that deal with physical space and deterministic architecture (Kornberger \& Clegg, 2003). While these studies are valuable in looking at specific meanings of space or learning or work, they have not accounted for the multiplicity of ways in which workers mobilize spaces for everyday learning. This paper draws on broader understandings of space, identity and learning, and suggests that an analysis of everyday learning in spatial terms can usefully open up spaces and opportunities for investigating and problematising workplace learning.

Such an analysis could also be undertaken in terms of time. For the sake of clarity of exposition, we restrict ourselves to space here. In many respects many of the remarks that follow could equally be couched in terms of time rather than place, or more accurately space/time.

\section{Background to the study}

The study reported here was undertaken as part of a research project funded by the Australian Research Council that examined learning in workgroups: 'Uncovering learning at work'. It followed from earlier outcomes from that project that focused on networking (Boud and Middleton 2003) and the naming of learning at work (Boud and Solomon 2003). Four work groups within a large organization were studied in detail over a three-year period. The employer is a public sector body involved in vocational 
education and training and two of the four workgroups were groups of teachers. Observations were made of the groups, interviews conducted and meetings held with the overall goal of examining and describing informal learning in the workplace and considering the implications of this in light of enhancing learning in the workplace. A particular feature of the research was the multiple layers of collaboration designed to engage participants with the project (Solomon et al 2001) (Details of the research can be found in the three papers cited). While learning more about learning spaces was not among our initial aims, space has emerged as a common theme in the data.

Concern about space and learning arose in our investigation of the experiences of members of work groups relating to learning at work. In interviewing participants, and in holding meetings with groups in their place of work, we found many references in transcripts to space and the ways in which it had significance for them. Given that the workplaces were part of an educational institution there were many predictable references to classrooms and offices as sites of learning. However these were accompanied by an entirely unanticipated set of references to learning spaces that were not usually considered to be either learning or working spaces. These included, meal breaks in staff rooms, coffee taken at local cafés and sharing transport with colleagues to and from work. These kinds of learning spaces may be described as 'work spaces' or 'socialising spaces' - but perhaps more appropriately they can be understood as hybrid spaces, that is, at one and the same time work and socialising spaces where the participants are both working and not working. This focus on social relationships in workplaces resonates with the cultural turn (du Gay 1996) and a contemporary foregrounding of social relationships and 'talk' in workplaces (Rhodes \& Scheeres 2004).

Throughout the interviews and meetings, participants continually referred to (things that we name as) 'space' in their discussions about their jobs in general. At first, these discussions were almost overlooked because of their 'normalness'. Indeed, initially there appeared to be a sense of banality about the 'spaces' we later identified as significant sites of everyday learning in our project. In a sense, this is misleading because the very banality highlighted their importance. Space is central because of its ubiquity. Space is perhaps important because it does not appear central. It is part of the context of learning that has been gaining greater recognition in considerations of 
learning from very many perspectives (eg. Lave and Wenger 1991, Duranti and Goodwin 1992, Rainbird 2004).

\section{The meaning of space}

In the literature some authors use the notion of 'space', others 'place' and yet others both, often to refer to similar things. While not wanting to elide differences in usage as part of other discussions, we are using them synonymously here. We are not referring only to literal physical spaces or places-although to some extent the physical spaces we encountered in the workplaces have prompted our interest in ideas around space. Our attention was also engaged by the materiality of physical spaces and their relationship with people.

Our spatial focus in part draws on writings associated with actor-network theory (Latour 1986 \& Callon 1986). It appeals because of its emphasis on space-time relations, networking, human and non-human relations and an understanding of power as association and effect rather than one of cause. The work of Nespor (1994) is particularly illuminating. While the concern of his work differs to ours as it examines university courses and the ways students are inducted into disciplines or professions, his work usefully brings us to an understanding of how local practices and relationships are enmeshed in more expansive disciplinary and professional networks. This means that while our focus is on local spaces, we also need to understand these spaces as not discrete or disconnected ones, but rather as ones that are linked to broader social relations and networks of power. Also, of relevance here, is that Nespor in examining the 'making of' physics and management students explored the disciplining work of the physical buildings of the programmes. He considered the physical spaces the students congregated in, where they played, where they studied, where they worked, the amount of time they spent in the building and how they filled 'their waking hours' $(1994,30)$.

As indicated above we are drawn to the notion of 'hybrid space' to name learning spaces at work that are considered to be and not to be working spaces. This naming of new learning spaces as hybrid spaces connects with the work of a number of cultural studies writers (such as Bhabha 1990 \& 1994; 1994 Said 1978; Rizvi 1997; Sarup 1996) who are concerned with identifying a third space that exposes the inadequacies of traditional binary oppositions and accompanying norms: 
... for me the importance of hybridity is not to be able to trace original moments from which the third emerges, rather hybridity to me is the third space which enables other positions to emerge. This third space displaces the histories that constitute it, and sets up new structures of authority, new political initiatives ... The process of cultural hybridity gives rise to something different, something new and unrecognisable, a new area of negotiation of meaning and representation. (Bhabha 1990, p 211)

While Bhabha's interest in a third space is in terms of challenging conventional boundaries around East and West, we find that 'third space' is also a useful metaphor for investigating the complexities of the somewhat non-transparent new identities, processes and relationships being produced at work in the contemporary workplace.

Indeed new ways of working, learning and being in the contemporary workplace is a consistent theme in organizational studies and educational literature (eg. Drucker 1993; Handy 1994; Gee et al 1996; Rose 1996; Marsick \& Watkins 1999). These writings draw attention to the complexities of organizations today and the way 'the organization has to become both a learning and a teaching organization' (Drucker 1993, 2). In other words these organizations as new spaces themselves are characterized by being both work and learning spaces where the boundary between the two is considerably blurred. In fact our project is generated by the very existence of this hybrid space, a space that enables/generates news ways of being, working and learning. Within this differently bounded space we, as a research team, in working collaboratively within a workplace in this particular moment of time are participating in a cross institutional network. And this network is constituted by participants aligned in terms of a particular set of shared interests. Moreover our presence in this research site and our refusal to take on a conventional researcher and researched relationship, our border crossing identities and practices are both cause and effect of the ambiguities and ambivalences around the boundaries of research and learning spaces (Stronach \& Maclure 1997).

The interest in workplaces making more use of informal learning while not necessarily translating it into formal learning, emerges within a 'new work order' (Gee et al 1996) which in itself is a site of resistance to conventional understandings, norms and binaries 
around, for example, an individual employee and their organization. In this context the concept of a hybrid space is a useful one in our investigations on uncovering learning at work, a task that could be readily understood as an investigation of the informal, rather than the formal.

As appealing as this third space is, it is also important not to over-romanticize it, imagining it to be unbounded, unregulated or undisciplined. As Nespor (1994) reminds us local practices (or spaces) are not disconnected from broader social networks of power. Hybrid spaces are not neutral spaces but are sites of contested and at times less visible disciplinary practices. So the third space under our current gaze is a space where the hierarchies within the (post)bureaucratic institution, the hierarchy implicit in any research relationship between academics and other professionals, as well as the internal complex politics of each of the workgroups, cannot be neutralized or discounted. In other words within this hybrid space there is no erasure of the previous identities of the workers or ourselves as they are practised in our various institutional positions. There are always traces and these traces may present themselves in multiple, and at times contradictory, practices and languages (Scheeres \& Rhodes 2003).

\section{Spaces within: some vignettes}

The discussion that follows draws on examples chosen from the individual interviews and feedback sessions with the workgroups. While they are only a sampling of the rich data that emerged around the thematic of space, these offerings serve to demonstrate the complexity of ways that space was talked about by the workers and the researchers in the transcripts.

We tried to understand the features of these hybrid learning spaces by examining: overlap periods (such as refreshment breaks) where workers are not 'entirely' workers

$\square$ actual spaces in work-places that are typically labelled as productive or nonproductive-such as workrooms or tearooms

talking spaces were people have conversations within or between work times (eg in a car driving home from work). 
These were not individual spaces where people engaged in solitary contemplation, but places where people gathered at various times. Relationships between people were continually being negotiated in these spaces. Arguably, there appears to be some lessening of the 'normal' workplace hierarchy—a kind of home territory that is not so much safe, but safer than formal meetings. In these spaces, the direction of 'talk' was not under the scrutiny of employers and some features of status temporally suspended. Topics of talk varied, people joked and it was not necessary to 'talk shop'.

In our examination of these places we were exploring them as spaces where what is said or not said is not as governed by institutional judgement, accountabilities and hierarchical positions as in other work spaces. However, in doing so we were also aware that our company influenced the dynamics within these spaces. We, the researchers, although attempting to be understood as co-participants in the project, were inevitably positioning ourselves and positioned by the employees in particular ways. As we and others have written (eg. Solomon et al 2001. Scheeres \& Solomon 2000) collaborative research projects are filled with complexities and tensions. They are not neutral spaces, but rather often sites of contestation.

The complexities around this hybrid space therefore cannot be underestimated. On the one hand we were seeking to 'uncover learning' that is everyday or informal learning (or learning that just happens), while on the other hand the act of uncovering requires an intervention, an intrusion, a judgement, and a formalising or a codifying in order to identify, articulate and manage it. While we were working in that space in a workplace that is also in the learning industry, at the same time we were strangers (or even space invaders), and as academics our business was similar but also different.

Nevertheless examining the hybrid or 'in-between' as useful sites of everyday learning was appealing and its appeal is demonstrated in the following comment from a trade teacher:

On my way here this morning I had a look at a job that the owner's not happy with. It's a townhouse in a block of four where the tiles are all cracking. There's no obvious reason for it. I've never seen it before in a cottage situation. And I was going to toss it around with these guys at lunchtime and see what they thought. 
This comment demonstrates many 'in-between’ spaces. First the geographical space between work and the participant's home. And there is also the temporal lunchtime, 'inbetween' sanctioned working hours. In both these spaces there is potentiality for learning. The teacher learned something new about the behaviour of tiles in cottages, and it is reasonable to imagine that during 'tossing it around with the guys at lunchtime' he also learned something new. The important point is that, neither of these 'between' spaces (travelling to work and lunchtimes) is generally considered a site of learning despite significant work related learning occurring.

A further example from this same group of trade teachers can be seen in the following comment when talking about their shared lunch room:

Well it's like we had someone talking to us from industry at lunchtime-it was pretty much an informal thing just over the lunch room we had a guy out from industry and he was talking to us about different changes, quite often we have stuff like that where someone from industry comes out and talks to us and we find out new ways of doing things.

Again, the lunchroom can be thought of as in-between on-the-job and off-the-job. And again, there is learning occurring. Indeed, it is learning that can significantly contribute to the productivity and effectiveness of this organization.

It was these comments, and many more like them, that prompted us to examine further the nature of these spaces. In the spirit of the collaboration we returned to the workgroups with our findings and it was here that the complexities of our research work came to the fore. The challenges in some groups of our naming of certain spaces as learning spaces triggered a number of questions that we needed to ask ourselves: Whose space was it to name in this way? Theirs? Ours? All of ours? Was it a new space? A different one? Indeed by considering these questions we could not help but consider the ways in which we, as researchers, have been troubled by, and further trouble, the complex collaborative researching of this workplace. 
The tensions around understanding and naming the hybrid spaces as learning spaces was particularly prominent with one of the workgroups involved in the study. It was the group of male trade teachers. This group had always presented itself in resistant ways, particularly when talking about learning through work and about being or not being learners. The ambivalence around this kind of talk is evident in the following quote:

Researcher: How do you learn from each other as a team of teachers, do you learn from each other?

Trade teacher: Well we don't ... OK, we do to an extent. Every lunchtime we're always sitting around the table and something will come up and we'll look at it there.

Another example came after one of the teachers had offered the anecdote cited earlier in this paper, drawing attention to the usefulness of talk around the lunch table. When one of the researchers attempted to name the tearoom space as an informal learning space, another teacher clearly resisted this suggestion:

Researcher: ... you know how we were talking about informal learning spaces and how the lunchroom is a good example of that. And there's a lot of everyday talk that goes on there and a lot of learning as well.

Trade teacher: I don't think we think about that as learning. I don't walk about there thinking I learned something today. To me it's not a learning environment. The classroom's a learning from me, to the student. The lunchroom sitting around here, it's not a learning environment at all. Even though I've learnt something.

Researcher: ... it seems to me a lot of learning takes place...

Trader teacher: I'm sure there is learning there all the time but I don't look at it as learning, if you know what I mean.

It appeared that the teacher regarded the naming of the lunchroom as a learning space as transgressive. He could admit that learning occurred, but to formally to acknowledge it as a learning space was to intrude into a protected environment.

At another encounter with this group of teachers, when the research team first entered the space, a short exchange occurred between colleagues before the tape recorder was switched on. The story was about the two teachers and their trip home together in a car. 
The teachers, who lived an hour or so away and consequently car-pooled, talked about a conversation that they had had about some challenges they were experiencing in their classroom. The teachers talked about how they exchanged experiences and ideas around these challenges and reported details of how they had debriefed together about the teaching demands of a difficult class. Curiously though, later in the 'formal' part of the feedback session, both teachers were adamant that they did not learn from each other.

It seems that the issue is not whether or not these teachers are learning while working or where this learning is taking place. Indeed there are many examples that suggest they are learning and they learn from each other in many different places. But rather the issue is how this learning is spoken about and who is initiating the talk. For example, while on the one hand, the researchers were sitting comfortably in the tearoom and chatting rather than interviewing, on the other hand, this comfort was not an untroubled one. Were we or were we not space invaders? Indeed when one teacher remarked 'I think you're reading too much into this' questions around our presence became very legitimate ones.

Non-ambivalent site: Work-based program teaching group However, our naming of in-between spaces as learning spaces was not met with the same resistance by all work groups. During feedback sessions with a group of teachers responsible for delivering workplace training we talked about points arising from the first round of interviews. They were invited to take up or challenge our points. The interviews had sparked interest for us in 'what' is learned and from 'whom', and we asked if they saw themselves learning from each other. One teacher began a lengthy conversation about their tearoom chats:

...we sit around the tea room a lot and every time we have a cup of tea we sit around I think the value without realising it is that we're analysing and reflecting and improving and discussing and its one of the things that keep you going.

A colleague added:

We make a cup of tea and solve the problem. 
There was general consensus among this group that tea room chats provided spaces where it was 'safe' to say things that couldn't be said in other situations. This group, and several others, told us that tea room chat went in many directions. There was an intermingling of work and non-work topics. It was a space where problems and ideas were 'brought in', exemplified by one worker telling us about 3am thoughts and how he took them to the tea room the following day... Guess what I thought of last night? he would ask.

These extracts suggest that this group was not resistant to our introduction of our language or to our physical presence and intrusion in their space. This is likely to be the case for a number of reasons. While they, like the trade teachers, had been teachers for many years, their current teaching program was a new one. It has a short history for them and the institution and it is a program that itself is crossing boundaries. Indeed throughout the project this group often voiced their frustrations with the pressures of working at the cutting edge of educational institution's prevailing commercial business whilst being limited by the workings of a large bureaucracy. They talked about the difficulties working in (and for) both public and private sector organizations. Their professional and personal spaces were already complicated hybrid ones.

Some members of another workgroup, as part of a discussion about workplace learning, referred critically to a staff development day, where staff from different units met to examine particular issues. In this organization it is typically arranged on a state-wide basis by a disciplinary grouping or staff development centre. After criticism of the value of such meetings at a time when there is so much work of one's own to do, one of them remarked:

It's usually run as a meeting where they give us information, and we've got the opportunity to ask questions. But one of the biggest values of it is that during the breaks, we network furiously. And it's amazing what you can pick up in terms of new ideas, or what's been tried and hasn't worked, when you've been thinking about trying the same thing. And you can modify it or adjust it because you've learnt from their experience just listening to them. 
While comments were made about the lack of opportunities in the formal sessions to do what one wanted, the occasion was more valued for what was not on the program, that is, it permitted contact with others with similar roles and discussing common issues. The informal spaces between sessions were valued for the learning opportunities they provided even when the legitimate program was not accorded much attention.

\section{Discussing the in-between}

Although our interpretation of 'spaces' were contested by some groups, and taking account of an awareness of our status as 'space invaders' we consider that naming these spaces as hybrid or 'in-between' offer some fruitful findings that have relevance beyond the study itself. For example, when considering the binaries that are so commonly accepted in workplaces: on-the-job/off-the-job, formal/informal, worker/social being, worker/learner, working/playing, productive/non-productive, the equally common privileging of the first of these pairs has to be unsettled. They no longer appear useful for thinking about learning in the workplace. It is in the in-between space that interesting things happen. As illustrated in some of the quotes above the important point is the 'in-between' spaces (such as travelling to work and lunchtimes) are generally considered sites of learning despite significant work related learning occurring.

In appearance, the physical spaces we have noticed can be described as transitional. For example, they are both work and socialising spaces. In the tearoom for example, while the furniture is 'homely', the space is not entirely 'homey either'. Similarly, the identities involved are transitional. When they enter these spaces they are neither entirely workers nor social beings, but located in between. Their activities are viewed as either working or socialising. They are not productive in the sense that they are performing the roles of normal work, yet the presence of significant learning means that they are not un-productive either.

Throughout our study we observed numerous ways in which participants resisted moves to formalise the informal. This ranged from denial that they were learning anything from each other (in the car trip), to exploiting the formal staff development day for their own ends, to avoiding the label of learner and rejecting our own prescriptions from the world of formal education. Occasions of reflection were overwhelmingly informal, but they could be seen as taking place close to the intersections of what Habermas (1986) 
refers to as the lifeworld and the system sphere of work and learning. Nonetheless, there was strong resistance to seeing reflection as part of the system world. Part of the original design of the research project was a stage in which some of the practices identified through the study would be developed as formal interventions to 'improve' learning at work. This idea was abandoned at an early point once it became clear that the richness of learning we identified could be compromised by attempting to move it into the system world of the organization. Welton (1995) has argued for the importance of adult educators protecting the lifeworld from such intrusions. It would seem that some of our participants had intuitively done the same as they perceived our interventions as system world intrusions-through naming learning and naming spaces as learning spaces_-into their lifeworld.

Awareness of the inappropriateness and limitations of binaries in conceptualising learning is illustrated well in other studies. The polarisation of formal and informal learning in particular has been thoroughly criticised by a recent study by Colley, Hodkinson and Malcolm. Their analysis of a large range of accounts in the literature indicate that the use of the apparently discrete categories of 'formal', 'informal' and 'non-formal' is to misunderstand the nature of learning. They suggest that it is more accurate to conceive 'formality' and 'informality' as attributes present in all circumstances of learning (Colley et al 2003). Similarly, our study points to the need to view learning spaces at work as simultaneously work and social and to see features of both in all settings.

Attempts to formalise learning spaces can inhibit the positive benefits of them, but the absence of formalisation may not necessarily foster it either. However there is always a risk in formalising the informal and our formal intrusions (through 'doing research') in some way influences the informal interaction. The effect of formalisation came up time and time again. When looking at learning at work using a spatial lens and thereby looking at spaces that are not normally considered to be learning spaces, but more like hybrid spaces, conventional binaries no longer seem appropriate. This seems to be particularly the case with the formal/informal binary. There we were looking at the informal, but in doing so, we were, wittingly or perhaps unwittingly, formalising it. It seems that by naming everyday learning as informal learning, this kind of learning can only be understood in relation to what it is not, that is formal learning. It is the binary 
that we seek to override, because we believe that it is the in-betweenness of the space that provides productive potential and once we start codifying or overcoding it, this potential can be lost.

\section{References}

Bhabha, H. K. (1994) The Location of Culture, (London: Routledge).

Bhabha, H. K. (Ed) (1990) Nation and Narration, (London: Routledge).

Boud, D. and Solomon, N. (2003) 'I don’t think I am a learner’: acts of naming learners at work, Journal of Workplace Learning, 15 (7/8), 326-331.

Boud, D. and Middleton, H. (2003) Learning from others at work: communities of practice and informal learning, Journal of Workplace Learning, 15 (5), 194-202.

Clarke, J., Harrison, R., Reeve, F., \& Edwards, R. (2002) Assembling spaces: the question of 'place' in further education. Discourse, 23 (3), 285-297.

Callon, M. (1986) Some elements of a sociology of translation, in: J. Law (Ed) Power, Action and Belief, (London: Routledge \& Kegan Paul), 196-233.

Colley, H., Hodkinson, P. and Malcolm, J. (2003) Informality and Formality in Learning. (London: Learning and Skills Research Centre).

Drucker, P. F. (1993) Concept of the Corporation, New Brunswick, N.J.: Transaction Publishers).

du Gay, P. (1996) Consumption and Identity at Work, (London: Sage).

Duranti, A. \& Goodwin, C. (Eds) (1992) Rethinking Context: Language as an Interactive Phenomenon, (Cambridge: Cambridge University Press).

Edwards, R., \& Clarke, J. (2002) Flexible learning, spatiality and identity. Studies in Continuing Education, 24 (2), 153-166.

Gee, J., Hull, G. \& Lankshear, C. (1996) The New Work Order: Behind the Language of the New Capitalism, (Sydney: Allen \& Unwin).

Groat, L. (1995) Introduction: Place, aesthetic evaluation and home, in: L. Groat (Ed.), Giving Places Meaning, (San Diego: Academic Press), 1-26.

Gusfield, J. (1987) Passage to play: rituals of drinking time in American society, in: M. Douglas (Ed) Constructive Drinking: Perspectives on Drinking from Anthropology, (Cambridge: Cambridge University Press), 73-90.

Habermas, J. (1986) The Theory of Communicative Action. Volumes One and Two. (trans. T. McCarthy). (London: Polity Press). 
Handy, C. (1994) The Empty Raincoat: Making Sense of the Future, (London Hutchinson Arrow).

Jamieson, P., Fisher, K., Gilding, T., Taylor, P., and Trevitt, C. (2000) Place and space in the design of new learning environments. Higher Education Research and Development, 19 (2), 221-237.

Kornberger, M., \& Clegg, S. (2003) The architecture of complexity. Culture and Organization, 9 (2), 75-91.

Latour, B. (1986) The powers of association, in: J. Law (Ed) Power, Action \& Belief: A New Sociology of Knowledge, (London: Routledge \& Kegan Paul), 264-280.

Lave, J. and Wenger, E. (1991) Situated Learning: Legitimate Peripheral Participation, (Cambridge: Cambridge University Press).

Marsick, V. \& Watkins, K. (1999) Facilitating Learning Organizations: Making Learning Count, (Aldershot, Hampshire: Gower).

O'Toole, K. M. P. (2001). Learning through the physical environment in the workplace. International Education Journal, 2 (1), 10-19.

Rainbird, H., Fuller, A. and Monroe, A. (Eds) (2004) Workplace Learning in Context. (London: Routledge).

Rizvi, F. (1997) Beyond the East-West divide: education and the dynamics of AustraliaAsia relations, The Australian Educational Researcher, 24 (1), 13-26

Rhodes, C. \& Scheeres, H. (2004) Developing people in organizations: working (on) identity, Studies in Continuing Education, 26 (2), 175-193

Rose, N. (1996) Inventing Our Selves: Psychology, Power, and Personhood, (Cambridge: Cambridge University Press).

Said, E. W. (1978) Orientalism, (London: Routledge \& Kegan Paul).

Sarup, M. (1996) Identity, Culture and the Postmodern Worlds, (Edinburgh: Edinburgh University Press).

Scheeres, H. (2003) Learning to talk: from manual work to discourse work as selfregulating practice. Journal of Workplace Learning, 15 (7/8), 332-338.

Scheeres, H. \& Solomon, N. (2000) Research partnerships at work: new identities for new times, in: J. Garrick \& C. Rhodes (Eds) Research and Knowledge at Work: Perspectives, Case Studies and Innovative Strategies, (London: Routledge), 178-199. 
Solomon, N., Boud, D., Leontios, M. and Staron, M. (2001) Tale of two institutions: exploring collaboration in research partnerships, Studies in the Education of Adults, 33 (2), 135-142.

Stronach, I. \& Maclure, M. (1997) Educational Research Undone: The Postmodern Embrace, (Buckingham: Open University Press).

Welton, M. (Ed.) (1995). In Defense of the Lifeworld: Critical Perspectives on Adult Learning, (Albany: State University of New York Press). 